\title{
Modeling of Academic Achievement of Primary School Students in Ethiopia Using Bayesian Multilevel Approach
}

\author{
Negusse Yohannes Sebro ${ }^{1} \&$ Ayele Taye Goshu ${ }^{1}$ \\ ${ }^{1}$ School of Mathematical and Statistical Sciences, Hawassa University, Hawassa, Ethiopia \\ Correspondence: Negusse Yohannes Sebro, School of Mathematical and Statistical Sciences, Hawassa University, \\ Hawassa, P.O.Box 05, Ethiopia. Tel: 251-911-97-2372. E-mail: negussiey@gmail.com
}

Received: December 24, 2016

Accepted: January 25, $2017 \quad$ Online Published: February 6, 2017

doi:10.5539/jel.v6n1p337

URL: http://dx.doi.org/10.5539/jel.v6n1p337

\begin{abstract}
This study aims to explore Bayesian multilevel modeling to investigate variations of average academic achievement of grade eight school students. A sample of 636 students is randomly selected from 26 private and government schools by a two-stage stratified sampling design. Bayesian method is used to estimate the fixed and random effects. Input and process quality indicators of education such as student to class ratio, student to teacher ratio, availability of teaching learning resources at school, teaching methods, and standard of course curriculum are found to be significantly affecting the academic achievement of the students. The effects of student level covariates: absence from class, academic motivation, academic self concept, study time, family income, mother's education, parents' employment status, work demand at home, and parent's follow-up of child are significantly varying from school to school. The results show that a large proportion of academic achievement variation is accounted to between schools. It is interesting to found out that the within school variation is very high for government schools while the between school variation is very high for private schools. There is uniformity across the government schools with high individual differences among students. However, there is lesser uniformity across the private schools with lesser individual differences of students. The findings in this study indicate that private schools are in a better position in maintaining quality of education at grade eight. Efficient academic management is needed at the government schools that can improve quality of education at the level.
\end{abstract}

Keywords: achievement, Bayesian multilevel, grade eight, primary school, students, variation

\section{Introduction}

Education is an important means of achieving sustainable economic development. It plays a vital role in optimal utilization of resources through development of human capital and improve their quality of life. Quality of human resources highly related to the quality of education (Battle \& Lewis, 2002). Educators and researchers have agreed upon on the nature of educational quality typically measured by achievement of students in national examinations (Pangeni, 2014; Mersha, Bishaw, \& Tegegne, 2013).

The quality of education remains top priority of research and long been interested in exploring predictors contributing effectively related to students, parents, teachers and schools (Mushtaq \& Nawaz Khan, 2012; Farooq, Chaudhry, Shafiq, \& Berhanu, 2011; McCoach et al., 2010; Salami, 2008; Sackey, 2007; Barnard, 2004; Jeynes, 2003). On the other hand, researches on academic achievement concluded that school level effects is less important than student level, i.e., no consistent relationship exists between school characteristics and academic achievement (Shera, 2014). By contrast, school characteristics: school environment, school type and school resources make a significant effect on student academic achievement (OECD, 2010b; Konstantopoulos, 2006). Consequently, researchers suggested and concluded that the effects of school and student level predictors vary and inconsistence across studies and countries context as result there is a longstanding debate of whether student or school characteristics have larger effects on academic achievement of students (Bowers \& Urick, 2011; Wobmann $\&$ West, 2006).

Multilevel models have gained dramatic application in educational data possessing a nested hierarchy and more generally for investigating uncertainty at different levels of aggregation (Raudenbush \& Bryk, 2002; Goldstein, 2011). Due to this nested structure of educational data the researchers agreed that multilevel model become a standard method for combining student and school level covariates for simultaneous estimation, extracting unobserved heterogeneity, decomposing and quantifying variations at student and school levels with associated 
predictors. It incorporates parameters that govern the dependence structure with complexity of errors structure. Bayesian method applies to address the parameters estimation problem in multilevel modeling (Loy, 2013; Snijders \& Berkhof, 2008; Hox, 2010; Perer, 2006).

Expansion of enrollment of primary schools alone is not sufficient unless the education system ensures the quality of education so that the students attain expected level of basic knowledge and skills. Studies have indicating that expansion of primary education in the country has compromising the quality. The quality of education remains challenging in most sub-Saharan African countries, including Ethiopia. Quality of educational output which can be measured by the achievement score of students on national examination is a crucial issue in low and middle income countries because of countries' efforts to maintain quality in the context of quantitative expansion of educational provision with limited resources (UNESCO, 2012; Grimm, 2011). Ethiopia is one of those countries which have placed strategies to increase quality of education with improving the academic achievement of students.

Ethiopia has made rapid expansion of gross enrollment rates of primary school from $20 \%$ in the early 1990 to $85.4 \%$ in 2010/2011 (MoE, 2012). Great efforts are made in expanding educational provision and opportunity, but not maintaining the expected quality of education. This is reflected on low academic achievement in national examination at the end of primary school (MoE, 2012). Students are often not equipped with the necessary numeracy, literacy and life skills at primary schools, and that there is a considerable challenge to meet the quality standards of education at primary schools in the country. The current study is thus to investigate contributing factors to the academic achievements of grade eight students, as a quality measure of education, and explore between and within school variations using Bayesian multilevel modeling.

\section{Data Description}

Target population is 7532 students who took grade eight national examination in the year 2009 GC at Hawassa city across 26 primary schools. A sample of 636 students is randomly selected using a two-stage stratified random sampling technique, with 468 students among 5733 from government schools and 168 students among 1799 from private schools. The data has a nested structure: student level with in school level. The sample size $n_{i}$ for student level is determined using the formula $n_{i}=N_{i} Z_{\alpha / 2}^{2} S_{i}^{2} /\left(N_{i} d^{2}+Z_{\alpha / 2}^{2} S_{i}^{2}\right)$ as given in Cochran (1909), where $N_{i}$ is total number of students at school type $i=1,2$ (government, private), $S_{i}^{2}$ is sample variance estimated from a

pilot survey, $Z_{\alpha / 2}=1.96$ is the critical value on the standard normal distribution at $\alpha=0.055$ significance level, and $d=0.02$ is margin of error.

The student's average achievement of grade eight national examinations, as outcome variable, is obtained from the Department of Education and Capacity Building of Hawassa City Administration. Average achievement is measure as scores out of $0-100 \%$. The respective primary data are collected on predictor variables from the identified students, teachers and school principals using a designed questionnaire and interviews.

\section{Multilevel Linear Model}

Educational data are often hierarchical in nature consequently classical regression models are not appropriate for analysis due to the presence of intra-class correlation within cluster which fail to take into account the nested nature of the data, consequences biased standard errors and estimates, but multilevel model allows simultaneous estimation of parameters from different levels and quantify between and within cluster variations (Guo, 2005; Singer \& Willet, 2003; Raudenbush \& Bryk, 2002). Bayesian method with non-informative prior is applied to this model to estimate the parameters using MCMCglmm R package (Finch, Bolin, \& Kelley, 2014; Bates, Maechler, \& Bolker, 2013; Snijders \& Bosker, 2012; Hox \& Roberts, 2011). Thus, the multilevel models to fit the primary school achievement data are given below. 


\subsection{Variance Components Model}

The variance components model has the form:

$$
Y_{i j}=\beta_{0}+U_{o j}+\varepsilon_{o i j}
$$

where $Y_{i j}$ is average academic achievement of $i^{\text {th }}$ student in $j^{\text {th }}$ school; $U_{o j}$ 's are school level random effects that are i.i.d. normally distributed with zero means and constant variances $\sigma_{\mathrm{u}}^{2} ; \varepsilon_{o i j}$ 's are errors that are i.i.d. normally distributed with zero means and constant variances $\sigma_{\varepsilon}^{2} ; \beta_{0}$ is overall average academic achievement.

The model decomposes the total variance into two-that of school and students levels, representing the between and within schools variabilities in the academic achievement of students (Hox \& Roberts, 2011). The interclass correlation (ICC) measures correlation between observation within cluster as:

$$
\text { ICC }=\frac{\sigma_{u}^{2}}{\sigma_{u}^{2}+\sigma_{\varepsilon}^{2}}
$$

\subsection{Random Intercept Model}

The model contains random intercept and fixed slopes for the covariates at both levels-it is given by:

$$
Y_{i j}=\underbrace{\beta_{0}}_{\substack{\text { overall } \\ \text { mean }}}+\underbrace{\beta_{1} X_{1 i j}+\ldots+\beta_{m}} X_{\text {school level }}+\underline{U_{0 j}}+\underbrace{\beta_{m+1}}+\underbrace{}_{m+1, i j}+\ldots+\beta_{p} X X_{p, i j}+\varepsilon_{i j}
$$

where $Y_{i j}$ is average academic achievement; $X_{m i j}$ 's is are covariates from the two levels and $\beta_{m}$ 's are fixed regression parameters to be estimated. Similarly $U_{o j}$ 's are school level random effects independently normally distributed with zero means and constant variances $\sigma_{u}^{2}$ and $\varepsilon_{o i j}$ 's are errors independently normally distributed with zero means and constant variances $\sigma_{\varepsilon}^{2}$.

\subsection{Random Coefficients Model}

This model is with varying intercept and slopes has the form:

$$
Y_{i j}=\underbrace{\beta_{0}}_{\begin{array}{c}
\text { overall } \\
\text { mean }
\end{array}}+\underbrace{\beta_{1} X_{1 i j}+\ldots+\beta_{m} X_{m i j}+U_{0 j}}_{\text {schoollevel }}+\underbrace{\beta_{m+1, j} X_{m+1, i j}+\ldots+\beta_{p j} X_{p, i j}+U_{1 j} X_{m+1, i j}+\ldots+U_{p j} X_{p, i j}+\varepsilon_{i j}}_{\text {studentlevel }}
$$

where the variables are same as equation (3) except the student level covariates are assumed to have random effects. School level predictors are kept fixed. The random effects $U_{o j}, U_{1 j}, \ldots, U_{p j}$ independently normally distributed with zero means and constant variances. $\varepsilon_{o i j}$ 's are errors independently normally distributed with zero means and constant variances $\sigma_{\varepsilon}^{2}$.

The Bayesian inferences all depend on the posterior distribution of the parameters given the data which is expressed in generic form as:

$$
\pi\left(\beta, \sigma_{U}^{2}, \sigma_{\varepsilon}^{2} \mid y, x\right) \quad \alpha \quad L\left(y, x \mid \beta, \sigma_{U}^{2}, \sigma_{\varepsilon}^{2}\right) \pi(\beta) \pi\left(\sigma_{U}^{2}, \sigma_{\varepsilon}^{2}\right)
$$


Fixed parameters are assumed to have normal distributions with large variances, and variances of the response variable and the random effects are assumed to have inverse gamma distributions. The Bayesian method is applied in the MCMCglmm R package (R Dev Core Team, 2013; Hadfield, 2010; Browne \& Draper, 2006; Gelman, 2006). With default non-informative prior distributions, the posterior distributions are simulated using Gibbs sampler until convergence and then estimates of the model parameters are computed.

\section{Results}

\subsection{Descriptive Analysis}

The total of 636 students considered in this study are who took grade eight national examination at the end of primary school from government and private schools of Hawassa City. The average academic achievement of students at private schools is (mean $\pm \mathrm{SD}$ ) $76 \pm 3.5$ and $35.1 \pm 4.1$ at government schools. It seems that students at private schools perform better than that of government schools. Students with very high academic motivation achieve $(45.36 \pm 12.17)$ which is higher than that of those with low academic motivation score (35.23 \pm 5.72$)$. Students who are absent from school most of the time achieve (33.15 \pm 4.03$)$ which is lower than that of those who are never absent (58.55 \pm 11.82$)$. Inferences are given here below.

\subsection{Results of Variance Components Model}

The results from analysis of variance components model (1) are displayed in Table 1. The results indicate that the overall average is significant and it is estimated to be $48.3 \%$ with standard error of 2.445 . The between and within school variations are also statistically significant at $5 \%$ significant level. About $79 \%$ of variation in the academic achievement of the students is accounted to the between schools, while $21 \%$ is accounted to the students.

Table 1. Bayesian variance components model $(\mathrm{n}=636)$

\begin{tabular}{|c|c|c|c|c|c|}
\hline \multirow{2}{*}{ Parameter } & \multirow{2}{*}{ Estimate } & \multicolumn{3}{|c|}{$95 \% \mathrm{CI}$} & \multirow{2}{*}{ Sign. } \\
\hline & & SE & LL & UL & \\
\hline \multicolumn{6}{|l|}{ Fixed part } \\
\hline Intercept & 48.3 & 2.445 & 43.52 & 53.11 & $0.000 *$ \\
\hline \multicolumn{6}{|l|}{ Random part } \\
\hline School variance & 153.6 & 49.685 & 77.98 & 254.10 & \\
\hline Residual variance & 40.1 & 2.329 & 35.80 & 44.66 & \\
\hline ICC & 0.79 & & & & \\
\hline DIC & 4152.20 & & & & \\
\hline
\end{tabular}

Note. $\mathrm{CI}=$ Confidence Interval, $\mathrm{LL}=$ Lower Limit, $\mathrm{UL}=$ Upper Limit, $\mathrm{SE}=$ Standard Error.

*Significance at $\alpha=0.05$.

\subsection{Results of Random Intercept Model with Covariates}

Results of analysis of the random intercept model (3) are displayed in Table 2. Intercept and several covariates are significant. There is much reduction of DIC to 3629.96 in model (3). The between and within school variations are statistically significant. About $43 \%$ of variation in the academic achievement of the students is accounted to the between schools, while $57 \%$ is accounted to the students level. The proportions of variations explained by the covariates are $R^{2}=92 \%$ for school level and $R^{2}=57.4 \%$ for student level.

Among covariates at the student level, the following are found significant at $5 \%$ significant level: student absence from class, academic motivation, academic self concept, study time, family income, availability of books at home, mother's education, parents' employment status, work demand at home, and parents follow-up of child. Sex is not significant. Academic achievement of a student at $8^{\text {th }}$ grade national exam can increase by increasing student non-absence from class, academic motivation of student, academic self concept, study time, family income, availability of books at home, mother's education, parents employment status, lowering work demand at home, and parents follow-up of child. School absenteeism and work load demand at home by parents are negatively associated with achievement. For instance, a student who is absent a unit of time is likely to reduces reduce his average achievement by $6.5 \%$. Increase in family income by a unit of currency increases achievement by $7.5 \%$. 
Parents need to reduce the time the student spends for household works and motivate the child to give more time for studying.

For the school level, the significant predictors are: teaching method, student to teacher ratio, student to class ratio, school distance from home, availability of teaching learning resources at school, student satisfaction with school environment and standard of curriculum. Teachers' motivation is not significant.

Quality indicators of education like student to class ratio, student to teacher ratio, instruction method in the class, availability of teaching-learning resources at school, and standard of curriculum are significantly related to the overall average academic achievement of students of the primary schools. Class size, student to teacher ratio and distance of school from home are negatively associated with student performance. Reducing student to class ratio and student to teacher ratio by a unit increases the academic achievement of a student by $9.6 \%$ and $3.4 \%$, respectively.

Table 2. Random intercept Bayesian model

\begin{tabular}{|c|c|c|c|c|c|}
\hline \multirow{2}{*}{ Parameter } & \multirow{2}{*}{ Estimate } & \multirow{2}{*}{ SE } & \multicolumn{2}{|c|}{$95 \% \mathrm{CI}$} & \multirow{2}{*}{ Sign. } \\
\hline & & & LL & UL & \\
\hline \multicolumn{6}{|l|}{ Fixed part } \\
\hline Intercept & 19.695 & 1.458 & 17.022 & 22.634 & $0.000^{*}$ \\
\hline \multicolumn{6}{|l|}{ Student level covariates } \\
\hline Sex & 0.648 & 0.352 & -0.073 & 1.310 & 0.064 \\
\hline Student absence from class (rev) & 6.498 & 0.801 & 4.794 & 7.940 & $0.000^{*}$ \\
\hline Academic motivation & 0.651 & 0.162 & 0.334 & 0.963 & $0.001 *$ \\
\hline Academic self concept & 1.656 & 0.778 & 0.078 & 3.045 & $0.030 *$ \\
\hline Time spent on study & 3.166 & 0.670 & 1.825 & 4.464 & $0.000 *$ \\
\hline Family income & 7.519 & 0.634 & 6.290 & 8.805 & $0.000 *$ \\
\hline Availability books at home & 0.412 & 0.193 & -0.012 & 0.743 & $0.038^{*}$ \\
\hline Mother education & 0.422 & 0.209 & -0.003 & 0.821 & $0.046^{*}$ \\
\hline Parents employment status & 1.342 & 0.556 & 0.352 & 2.491 & $0.016^{*}$ \\
\hline Work demand at home (rev) & 0.427 & 0.183 & 0.044 & 0.751 & $0.020^{*}$ \\
\hline Parents follow-up of child & 2.087 & 0.630 & 0.874 & 3.307 & $0.000 *$ \\
\hline \multicolumn{6}{|l|}{ School level covariates } \\
\hline Teaching method & 2.136 & 0.767 & 0.686 & 3.602 & $0.004 *$ \\
\hline Teachers motivation & 3.005 & 1.694 & -0.183 & 6.269 & 0.076 \\
\hline Student to class ratio (rev) & 9.583 & 1.844 & 6.186 & 13.092 & $0.000^{*}$ \\
\hline Student to teacher ratio (rev) & 3.470 & 1.689 & 0.298 & 6.813 & $0.042 *$ \\
\hline School distance from home (rev) & 0.926 & 0.406 & 0.193 & 1.719 & $0.014 *$ \\
\hline Teaching resources at school & 1.172 & 0.575 & 0.014 & 2.217 & $0.044 *$ \\
\hline Students satisfaction on school & 1.611 & 0.668 & 0.266 & 2.914 & $0.028 *$ \\
\hline Standard of curriculum & 2.314 & 0.709 & 1.041 & 3.826 & $0.000 *$ \\
\hline \multicolumn{6}{|l|}{ Random part } \\
\hline School variance & 12.87 & 4.777 & 5.689 & 21.78 & \\
\hline Residual variance & 17.08 & 1.026 & 15.04 & 18.94 & \\
\hline ICC & 0.430 & & & & \\
\hline DIC & 3629.960 & & & & \\
\hline
\end{tabular}

Note. $\mathrm{CI}=$ Confidence Interval, $\mathrm{LL}=$ Lower Limit, $\mathrm{UL}=$ Upper Limit; $\mathrm{SE}=$ Standard Error.

*Significance at $\alpha=0.05$; rev: variable measured in reverse order so as to see positive effect. 


\subsection{Results of Random Coefficients Model with Covariates}

Results of analysis of the Bayesian random coefficients model (4) are displayed in Table 2. The Bayesian approach has provided more precise estimates of the model parameters as compared to the likelihood methods. The results show that the random effects are significant. Intercept and several covariates are significant. The DIC $=3624.42$ of this model (4) is the lowest, showing that the Bayesian random coefficients model is best fitting to the data. The between and within school variations are statistically significant. About $41.5 \%$ of variation in the academic achievement of the students is accounted to the between schools, while $58.5 \%$ is accounted to the students level.

Among covariates at the student level, the following are found significant at $5 \%$ significant level: student absenteeism, academic motivation of students, academic self concept, study time, family income, mother's education, parents employment status, work demand at home, and parents follow-up of child. Sex and availability of books at home are not significant. Academic achievement of a student at $8^{\text {th }}$ grade national exam can be increased by increasing student non-absence from class, academic motivation of student, academic self concept, study time, family income, mother's education, parents employment status, lowering work demand at home, and parents follow-up of child. Absence from class and high work time at home activities are negatively related with a student's achievement, while study time has positive effect. For instance, a student who is absent a unit of time is likely to reduce his average achievement by $6.5 \%$. Increase in family income by a unit of currency increases achievement by $7.5 \%$. Parents need to reduce the time the student is to spend for household works and rather motivate the child to give more time for studying and doing home works. Parent's follow-up of the child is so important that the child always goes to school and gets proper education. Academic motivation and self concept are to be boosted by teachers and parents.

For the school level, the significant predictors are: teaching method, student to teacher ratio, student to class ratio, school distance from home, availability of teaching learning resources at school, student satisfaction with school environment and standard of curriculum. Teachers' motivation is not significant. Indicators of quality of education such as teaching method, student to class ratio, student to teacher ratio, and standard of the curriculum are significantly affecting the academic achievement of students. Class size, student to teacher ratio and distance of school from home are negatively related to the student performance. Reducing student to class ratio and student to teacher ratio by unit increases academic achievement of a student by nearly $9.4 \%$ and $3.3 \%$, respectively. Reducing distance of home to school by ten kilometers can increase achievement of the student by nearly $10 \%$. Ministry of education needs to optimally locate primary schools to reduce school distance from villages and households.

Table 3. Random coefficients Bayesian model

\begin{tabular}{|c|c|c|c|c|c|}
\hline \multirow{2}{*}{ Parameter } & \multirow{2}{*}{ Estimate } & \multirow{2}{*}{ SE } & \multicolumn{2}{|c|}{$95 \% \mathrm{CI}$} & \multirow[t]{2}{*}{ Sign. } \\
\hline & & & LL & UL & \\
\hline \multicolumn{6}{|l|}{ Fixed part } \\
\hline Intercept & 20.477 & 2.955 & 16.016 & 24.883 & $0.002 *$ \\
\hline \multicolumn{6}{|l|}{ Student level covariates } \\
\hline Sex & 0.604 & 0.343 & -0.098 & 1.222 & 0.08 \\
\hline Student absence from class (rev) & 6.188 & 5.487 & 0.949 & 11.653 & $0.048^{*}$ \\
\hline Academic motivation & 0.690 & 0.158 & 0.382 & 0.991 & $0.00^{*}$ \\
\hline Academic self concept & 1.508 & 0.794 & -0.044 & 3.034 & $0.046^{*}$ \\
\hline Time spent on study & 3.046 & 0.699 & 1.727 & 4.492 & $0.00^{*}$ \\
\hline Mother education & 0.395 & 0.206 & 0.016 & 0.813 & $0.048^{*}$ \\
\hline Family income & 7.528 & 0.622 & 6.379 & 8.781 & $0.000 *$ \\
\hline Parent employment status & 1.307 & 0.691 & 0.156 & 2.567 & $0.040^{*}$ \\
\hline Availability of books at home & 0.370 & 0.227 & -0.079 & 0.750 & 0.084 \\
\hline Work demand at home (rev) & 0.463 & 0.184 & 0.130 & 0.840 & $0.010^{*}$ \\
\hline Parents follow-up of child & 2.206 & 0.703 & 1.040 & 3.507 & $0.004 *$ \\
\hline
\end{tabular}




\begin{tabular}{|c|c|c|c|c|c|}
\hline \multicolumn{6}{|l|}{ School level covariates } \\
\hline Teaching method & 2.311 & 0.762 & 0.720 & 3.685 & $0.006 *$ \\
\hline Teachers motivation & 3.017 & 1.738 & 0.502 & 6.237 & 0.092 \\
\hline Student to class ratio (rev) & 9.384 & 1.763 & 6.043 & 12.957 & $0.001 *$ \\
\hline Student to teacher ratio (rev) & 3.317 & 1.737 & 0.084 & 6.913 & $0.040 *$ \\
\hline School distance from home (rev) & 0.985 & 0.429 & 0.140 & 1.816 & $0.028^{*}$ \\
\hline Teaching resources at school & 1.079 & 0.567 & -0.047 & 2.095 & $0.048^{*}$ \\
\hline Student satisfaction on school & 1.653 & 0.656 & 0.454 & 2.897 & $0.014 *$ \\
\hline Standard of curriculum & 2.218 & 0.722 & 0.946 & 3.744 & $0.002 *$ \\
\hline \multicolumn{6}{|l|}{ Random effects } \\
\hline School variance & 11.930 & 4.583 & 4.655 & 20.200 & \\
\hline Residual variance & 16.800 & 1.046 & 14.790 & 18.810 & \\
\hline Student absence from class (rev) & 4.004 & 6.396 & & & \\
\hline Academic motivation & 0.131 & 0.056 & & & \\
\hline Availability of books at home & 0.105 & 1.663 & & & \\
\hline Parent employment status & 0.115 & 1.297 & & & \\
\hline ICC & 0.415 & & & & \\
\hline DIC & 3624.419 & & & & \\
\hline
\end{tabular}

Note. $\mathrm{CI}=$ Confidence Interval, $\mathrm{LL}=$ Lower Limit, $\mathrm{UL}=$ Upper Limit, $\mathrm{SE}=$ Standard Error.

*Significance at $\alpha=0.05$ rev: variable measured in reverse order so as to see positive effect.

\subsection{Variance Components Models by School Type}

The Bayesian analyses of variance components are conducted for the government and private schools data separately. Results are given in Table 4 . The results indicate that the between school variation is about $1 \%$ for the government schools and $67 \%$ for private schools. There is high similarities among the government schools. However, there is very high within school variation (99\%) for government schools as compared to $33 \%$ for within private schools. The findings reveal that there is high achievement variation at government schools due to students individual differences. On the contrary, there is lower achievement variation at private schools and higher. It seems that individual differences are managed to be lower as compared to that of government ones while they still maintain higher variation between them-possibly due to competition and efficient academic management.

Table 4. Bayesian variance components model by school type

\begin{tabular}{|c|c|c|c|c|c|c|c|c|}
\hline \multirow{3}{*}{ Parameter } & \multicolumn{4}{|c|}{ Government School } & \multicolumn{4}{|c|}{ Private School } \\
\hline & \multirow{2}{*}{ Estimate (SE) } & \multicolumn{2}{|c|}{$95 \%$ CI } & \multirow{2}{*}{ Sign. } & \multirow{2}{*}{ Estimate (SE) } & \multicolumn{2}{|c|}{$95 \% \mathrm{CI}$} & \multirow{2}{*}{ Sign. } \\
\hline & & LL & UL & & & LL & UL & \\
\hline \multicolumn{9}{|l|}{ Fixed part } \\
\hline Intercept & $38.8(0.333)$ & 38.15 & 39.45 & $0.00 *$ & $58.0(3.073)$ & 51.47 & 63.67 & $0.00 *$ \\
\hline \multicolumn{9}{|l|}{ Random part } \\
\hline School variance & $0.36(0.830)$ & 0.00 & 2.29 & & $109.5(56.2)$ & 28.35 & 222.60 & \\
\hline Residual variance & $36.8(2.507)$ & 32.26 & 41.15 & & $52.8(6.25)$ & 41.10 & 64.93 & \\
\hline ICC & 0.01 & & & & 0.67 & & & \\
\hline
\end{tabular}

Note. $\mathrm{CI}=$ Confidence Interval, $\mathrm{LL}=$ Lower Limit, $\mathrm{UL}=$ Upper Limit; $\mathrm{SE}=$ Standard Error.

*Significance at $\alpha=0.05$. 


\section{Conclusions}

This study aims to explore Bayesian multilevel modeling to investigate variations of average academic achievement of grade eight school students in Ethiopia. A sample of 636 students is randomly selected from 26 private and government schools based on a two-stage stratified sampling. Academic achievement is considered as a quality measure of education. Between and within school variations are studied.

The Bayesian method has provided more precise estimates of model parameters as compared to the likelihood methods. The Bayesian random coefficients model best fits to the data. The Bayesian random intercept model is in equivalent performance and can be interpreted.

The factors identified to be significantly affecting achievement of students are: (1) for student level: student absence from class, academic motivation of students, academic self concept, study time, family income, mother's education, parents employment status, work demand at home, and parents follow-up of child; (2) for school level: the significant predictors are: teaching method, student to teacher ratio, student to class ratio, school distance from home, availability of teaching learning resources at school, student satisfaction with school environment and standard of curriculum. Sex, availability of books at home, and teachers' motivation are not significant.

There are achievement variations due to between schools and within schools at the primary schools. Variation of $41.5 \%$ is accounted to the between schools and $58.5 \%$ to the students. For government schools, the between school variation is quite low $(1 \%)$ and within school variation is very high $(99 \%)$. So, there is high uniformity across the schools and high individual differences among students. High uniformity may mean less completion. However, for private schools the between school variation is fairly high (67\%) and the within school variation is reasonably low $(33 \%)$. There is lesser uniformity across the schools and lesser individual differences among students. This may be possibly due to the current practice of competition and efficient academic management at the private schools. The findings in this study indicate that private schools are in a better position in maintaining quality of education at grade eight.

Due to the fact that national examination at the end of primary school measures overall quality of education at that level, the findings imply that quality of primary education varies from school to school and is significantly affected by the input and the process variables. This may indicate certain inequities in the school system. The government needs to intervene based on the input indicators investigated in this study in order to improve the teaching and learning environment at the primary schools in the country. A lot can be learnt from both government and private school practices. Parents need to financially and morally support their children to always go to school and get proper education. They are also to reduce work load of the children and rather motivate them to give more time for studying and doing home works. Teachers and school system need to boost academic motivation and self concept the students.

\section{References}

Barnard, W. M. (2004). Parent involvement in elementary school and educational attainment. Children and Youth Services Review, 26, 39-62. https://doi.org/10.1016/j.childyouth.2003.11.002

Bates, D., Maechler, M., \& Bolker, B. (2013). lme4: Linear mixed-effects models using S4 classes. R Package Version 0.999999-0.

Battle, J., \& Lewis, M. (2002). The increasing significance of class: The relative effects of race and socioeconomic status on academic achievement. Journal of Poverty, 6(2), 21-35. https://doi.org/10.1300/J134v06n02_02

Bowers, A. J., \& Urick, A. (2011). Does high school facility quality affect student achievement? A two-level hierarchical linear model. Journal of Education Finance, 37(1), 72-94.

Browne, W. J., \& Draper, D. (2006). A comparison of Bayesian and likelihood-based methods for fitting multilevel models. Bayesian Analysis, 1(3), 473-514.

Cochran, W. (1909). Sampling techniques (3rd ed.). John Wiley and Sons.

Farooq, M. S., Chaudhry, A. H., Shafiq, M., \& Berhanu, G. (2011). Factors affecting students' quality of academic performance: A case of secondary school level. Journal of Quality and Technology Management, 7(2), 1-14.

Finch, W. H., Bolin, J. E., \& Kelley, K. (2014). Multilevel modeling using R. Chapman \& Hall/CRC, Statistics in the Social and Behavioral Sciences Series.

Gelman, A. E. (2006). Prior distributions for variance parameters in hierarchical models. Bayesian Analysis, 1, 513-533.

Goldstein, H. ( 2011). Multilevel statistical models. In Wiley Series in Probability and Statistics (4th ed.). 
Grimm, M. (2011). Does household income matter for children's schooling: Evidence for rural Sub-Saharan Africa. Economics of Education Review, 30(4), 740-754. https://doi.org/10.1016/j.econedurev.2011.03.002

Guo, S. (2005). Analyzing grouped data with hierarchical linear modeling. Children and Youth Services Review, 27, 637-652. https://doi.org/10.1016/j.childyouth.2004.11.017

Hadfield, J. D. (2010). MCMC methods for multi-response generalized linear mixed models: The MCMCglmm R Package. Journal of Statistical Software, 33(2), 1-22. https://doi.org/10.18637/jss.v033.i02

Hox, J. (2010). Multilevel analysis: Techniques and applications (2nd ed.). Routledge, New York.

Hox, J., \& Roberts, K. R. (2011). Handbook of advanced multilevel analysis. Wiley Series in Probability and Statistics.

Jeynes, W. H. (2003). A meta-analysis: The effects of parental involvement on minority children's academic achievement. Education and Urban Society, 35(2), 202-218. https://doi.org/10.1177/0013124502239392

Konstantopoulos, S. (2006). Trends of school effects on student achievement: Evidence from NLS: 72, HSB: 82, and NELS: 92. Teachers College Record, 108(12), 2550-2581. https://doi.org/10.1111/j.1467-9620.2006.00796.x

Loy, A. (2013). HLMdiag: Diagnostic tools for hierarchical (multilevel) linear models. R Package Version 0.2.2.

McCoach, D. B., Goldstein, J., Behuniak, P., Reis, S. M., Black, A. C., Sullivan, E. E., \& Rambo, K. (2010). Examining the unexpected: Outlier analyses of factors affecting student achievement. Journal of Advanced Academics, 21(3), 426-468. https://doi.org/10.1177/1932202X1002100304

Mersha, Y., Bishaw, A., \& Tegegne, F. (2013). Factors affecting female students' academic achievement at Bahirdar University. Journal of International Cooperation in Education, 15(3), 135-148.

MoE. (2012). Education statistics annual abstract. Addis Ababa, Ethiopia, Ministry of Education.

Mushtaq, I., \& Nawaz Khan, S. (2012). Factors affecting students' academic performance. Global Journal of Management and Business Research, 12(9), 16-22.

OECD. (2010b). PISA 2009 Results: What makes a school successful? Resources, Policies and Practices (Vol. IV). PISA, OECD, Paris.

Pangeni, K. P. (2014). Factors determining educational quality: Student mathematics achievement in Nepal. International Journal of Educational Development, 34, 30-41. https://doi.org/10.1016/j.ijedudev.2013.03.001

Perer, C. (2006). Bayesian statistical modeling (2nd ed.). Wiley Series in Probability and Statistics.

$\mathrm{R}$ Dev Core Team. (2013). R: A language and environment for statistical computing. R Foundation for Statistical Computing, Vienna, Austria.

Raudenbush, S. W., \& Bryk, A. S. (2002). Hierarchical linear models: Applications and data analysis methods (2nd ed.). Thousand Oaks, CA: Sage Publications.

Sackey, H. (2007). The determinants of school attendance and attainment in Ghana: A gender perspective. Nanaimo, Canada: Malaspina University-College.

Salami, S. O. (2008). Roles of personality, vocational interests, academic achievement and socio-cultural factors in educational aspirations of secondary school adolescents in southwestern Nigeria. Career Development International, 13(7), 630-647. https://doi.org/10.1108/13620430810911092

Shera, P. (2014). School effects, gender and socioeconomic differences in reading performance: A multilevel analysis. International Education Studies, 7(11). https://doi.org/10.5539/ies.v7n11p28

Singer, J. D., \& Willet, J. B. (2003). Applied longitudinal data analysis: Modeling change and event occurrence. New York, NY: Oxford University Press. https://doi.org/10.1093/acprof:oso/9780195152968.001.0001

Snijders, T. A., \& Bosker, R. J. (2012). Multilevel analysis: An introduction to basic and advanced multilevel modeling (2nd ed.). Sage, London.

Snijders, T., \& Berkhof, J. (2008). Diagnostic checks for multilevel models. In J. de Leeuw, \& E. Meijer (Eds.), Handbook of Multilevel Analysis (Chapter 3, pp. 141-175). Springer Verlag, New York. https://doi.org/10.1007/978-0-387-73186-5_3 
UNESCO. (2012). Financing education in Sub-Saharan Africa meeting the challenges of expansion, equity and quality. UNESCO Institute for Statistics.

Wobmann, L., \& West, M. (2006). Class-size effects in school systems around the world: Evidence from between-grade variation in TIMSS. European Economic Review, 50(3), 695-736. https://doi.org/10.1016/j.euroecorev.2004.11.005

\section{Copyrights}

Copyright for this article is retained by the author(s), with first publication rights granted to the journal.

This is an open-access article distributed under the terms and conditions of the Creative Commons Attribution license (http://creativecommons.org/licenses/by/4.0/). 